\title{
Help eradicate HPV-related cancer
}

We are all familiar with studies that are evidence-based, but how relevant are they to everyday life? Frequently we find ourselves saying, 'that's all very well in a research laboratory but how does it work in the real world?'

Oral-B wants dental professionals to see the benefits of their products at first hand. Dental professionals are invited to participate in a 'Patient Evaluation Programme' (PEP) for their new Gum and Enamel Repair Toothpaste. This new toothpaste helps patients address the increasing prevalence of gum or enamel issues. Featuring unique ActivRepair technology (with two sources of stannous: stannous fluoride and stannous chloride), it is the best clinically proven toothpaste from Oral-B to help restore gum health and prevent enamel erosion.

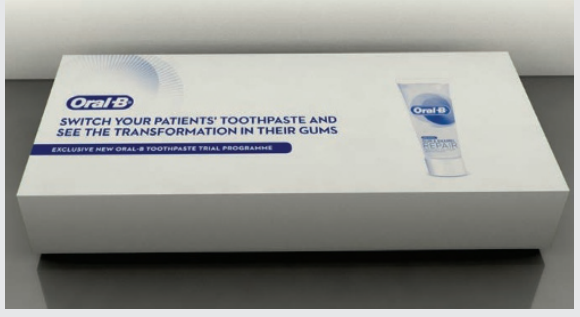

The PEP is simple to run. Simply select three patients you think would benefit from using the product. Assess and record their oral health status at the start of the programme and then again three months later. Each kit contains $10 \times 75 \mathrm{ml}$ tubes of toothpaste (three per patient, plus one for your own use) and a simple tick-box assessment sheet.

Oral-B will donate $£ 5$ to HPV Action for every completed form returned by the end of March 2018. HPV is a main causative factor for oral cancer. HPV Action is campaigning to extend the national immunisation programme to include boys. Each year over 2,000 men in the UK are diagnosed with a HPV-related cancer, of whom almost half will die from the condition within five years.

Oral-B is also using the PEP programme as an opportunity to support the BSDHT and BADT's 'Next Steps to Exemptions' initiative and will donate $\mathfrak{£} 5$ to the campaign for each form received from a hygienist/therapist. The aim of the campaign is for dental hygienists and dental therapists to be able to administer or supply specified prescription-only medicines, such as local anaesthetic, topical anaesthetic and fluoride varnishes. For more information on the campaign log onto www. bsdht.org.uk/exemptions.

If you would like to participate in Oral-B's PEP contact your Oral-B representative.

\section{Diamond status restorations}

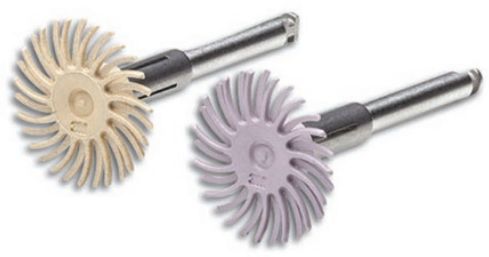

Give your restorations a diamond finish with the Sof-Lex diamond polishing system from 3M Oral Care.

Allowing you to quickly and easily achieve highly aesthetic results, the Sof-Lex diamond polishing system helps to create a natural gloss in only two steps.

1. The pre-polishing spirals smooth and remove small scratches on the restoration in preparation for final polish

2. The diamond-impregnated polishing spirals create a smooth, high gloss finish.

Its unique, flexible shape and its ability to adapt to all surfaces make it ideal in a range of different cases. Plus, the system is reusable for a highly cost-effective solution.

To find out more and to give all your restorations a diamond status, discover the Sof-Lex diamond polishing system from 3M Oral Care.

For more information, call 08456025094 or visit www.3m.co.uk/oralcare

$3 \mathrm{M}$ and Sof-Lex are trademarks of the $3 \mathrm{M}$ Company.

\section{Minimise the discomfort of local analgesia}

No matter how good you are at delivering local anaesthesia, the chances are that your patients will still be very fearful of the procedure. Well, there's a way round it: The Wand is a computer-controlled-anaesthetic delivery system that pushes the anaesthetic solution of your choice through a needle. The rate and pressure of delivery is what allows you to get your anaesthetic to where it is needed without much of the traditional discomfort/pain that is associated with using a syringe.

The lightweight handpiece is a $15 \mathrm{~cm}$ plastic tube that is held in a comfortable pen grip, providing an increase in tactile sensation and control. For the needle phobic patient, this will dispel all their preconceptions of dental treatment, but it would be a waste to limit its use to such a small group. All patients will be grateful for you minimising the discomfort of local analgesia. Most patients report not actually feeling a thing when The Wand administers its magic!

The Wand is now distributed exclusively by Dental Sky. To request a demo call 0800 2944700 or email sales@dentalsky.com.

\section{A referral centre of excellence}

The Priors Dental Practice Referral Centre is a multidisciplinary centre of excellence based in Staffordshire, dedicated to the provision of the highest standard of care to referring dentists and their patients. Its clinicians are experts in their fields, using the latest equipment and advancements in technology within dentistry, and are committed to offering exceptionally high levels of service. The professional skills and expertise provided by the Priors' experienced team make it a natural choice for GDPs wanting the best possible care for their patients.

Following the completion of treatment, patients are returned to the referring practice for their ongoing dental care.

Find out more online at www.thepriorsdentalpractice.co.uk, by emailing info@thepriorsdentalpractice.co.uk or calling 01785712388 . 